\title{
LVI. New outlines of chemical philosophy
}

\section{Ez. Walker Esq.}

To cite this article: Ez. Walker Esq. (1814) LVI. New outlines of chemical philosophy, Philosophical Magazine Series 1, 44:199, 350-355, DOI: 10.1080/14786441408637467

To link to this article: http://dx.doi.org/10.1080/14786441408637467

曲 Published online: 27 Jul 2009.

Submit your article to this journal 준

III Article views: 2

Q View related articles $₫$ 
It is unnecessary to enter more fully into the discussion of a position so discordant with phanomena and so limited in its application.

Such is a statement and short examination of the systern laid down by Franklin to explain the phænonena of electricity: a system which from its novelty, ingenuity, and from the modesty of its illustrious inventor, was received with admiration by most philosophers of that day. The charms of novelty are now no more, the catalogue of facts is increased, neither prepossession nor prejudice are likely at this distance of time to influence judgement : the imperfections of the hypothesis may therefore be fairly appreciated. And yet this hypothesis is always referred to as the basis of the doctrines of Galvanism. In the present dignified and improved state of natural science every thing should be rejected without reserve, without respect to authority, that deviates from the standard of reason and experiment.

[To be continued.]

LVI. New Outlines of Chemical Philosophy. By Ez. WaLrer, Esq. of Lynn, Norfolk.

[Continued from p. 274.]

On Evaporation, Hail, Rain, Snow, and Dew.

$\mathbf{I}_{\mathrm{T} \text { has been ascertained hy observation that the mean annual }}$ quantity of rain is greatest at the equator, and decreases gradually as we approach the poles. 'Thus at

Granada*, Antilles, $12^{\circ}$ N. lat. it is 126 inches.

Cape François *, St. Domingo .... $19^{\circ} 46^{\prime} 120$ inches.

Calcuttał................22 $23 \quad 81$

Rome $f \ldots \ldots \ldots \ldots \ldots \ldots \ldots \ldots . \ldots 1 \quad 54 \quad 39$

England $\S \ldots \ldots \ldots \ldots \ldots \ldots \ldots \ldots . \ldots 33 \quad 00 \quad 32$

Petersburg $\| \ldots \ldots \ldots \ldots \ldots \ldots \ldots .59 \quad 16 \quad 16$

Hence it appears that the quantity of rain is influenced by the heat of the climate. - But as the sun's rays have no heat in themselves, what is the reason that they generate heat upon the surface of our earth.

To solve this important question it is necessary to premise, that no combustion nor increase of temperature can be produced, unless thermogen and photogen be united to ponderable matter.

* Cotte, Jour. de Phys. Oct. 1791, p. 261.

$\uparrow$ Asiatic Researches, 1 and 2 Appendix.

I Cotte, Jour. de Phys, Oct. 1791, p. 264.

\$ Pbil. Trans. $\quad||$ Edin. Trans. ii. p. 944. 
Now it is evident from common observation, that the sun's rays have the power of increasing the temperature of bodies; hence it was supposed that the sun was the fountain of heat. But this hypothesis is now found to be erroneous, for the sun's rays have in heat in themselves*, but they possess the power of acting upon the elements of heat and light, thermogen and photogen, contained in bodies so as to increase their temperature.

When the thermogen and photogen which lie dormant in matter upon the earth's surface, are acted upon by the sun's rays, those elements attract each other, and as they have a strong attraction for moisture $\uparrow$, a chemical union takes place between them and the water upon the surface of the earth, and two new gases are formed. Photogen and water form hydrogen gas, which ascends to the upper regions of the atmosphere, far above the altitude to which any balloon can ascend. Hence the reason that no hydrogen gas has been found in the atmosphere near the earth's surface.

The new oxygen gas, formed at the same time by the chemical union of thermogen and moisture, being much heavier than the other gas, because it contains more moisture, rises to a much less altitude. Hence it follows that all the moisture which is carried off from the earth's surface is converted into oxygen and hydrogen gases, consequently the atmosphere contains a much larger portion of those gases at one time than at another, and therefore its weight is variable, as shown by the barometer.

When a Leyden jar is highly charged, the two elements which it contains attract each other, and a spark is produced with a loud report. In like manner, when the thermogen in the lower regions of the atmosphere attracts the photogen from the upper, the same phænomena take place, called thunder and lightning. The only difference between the operations of nature to restore the lost equilibrium, and the effects observed in our experiments, consists in magnitude not in principle.

\section{Thunder, Lightning, and other Meteors arising from the Com- position and Decomposition of the Air.}

When oxygen and hydrogen gases are mixed together, and a single electric spark introduced, combustion instantly takes place; and as the portion of the gases thus mixed together in the atmosphere may extend over a circle of some miles in diameter, the lightning may be the aggregate of the elements of combustion contained in that space.

* Phil. Mag. vol. xlii. p. 370. † + Phil. Mag. vol. xliii. p. 252.

Water 
Water being 914 times heavier than an equal bulk of atmospheric air, it will be easily conceived, that when the oxygen and hydrogen gases, contained within a circle of many miles in diameter, are reduced into water, an immense vacuum must be instantaneously formed; and, consequently, the air rushing into it must produce a violent concussion, accompanied with a tremendous report.

Hence the reason that the wind blows towards a thunder cloud; and a fresh portion of oxygen gas being thus mixed with the hydrogen gas which remains unconsumed, a second report succeeds the first; and thus thunder will be continued as long as any hydrogen gas remains unconsumed.

The extent of the influence of the two elements upon each other to decompose the air, may be estimated, in sone degree, by the breadth of the shower: not by its length, for that may be influenced by the wind.

The quicksilver falls in the barometer during a thunder storm, because the atmosphere is lighter, part of it having been converted into a heavy shower of rain; but when the shower is over and evaporation recommencing, the water being again converted into air, the atmosphere becomes heavier and the quicksilver rises. When the chemical union between water and the two elements of conbustion is dissolved, those elements descend to the earth with the falling rain; hence the reason that the air becomes colder after a shower; and the reason that we have no thunder in a rainy season is this; the elements of combustion are conducted back again to the earth, as fast as they ascend into the atmosphere.

If the mean annual quantity of water whieh rises by evaporation be equal to the mean annual quantity of rain, there must be ten feet six inehes of water converted into atmospherie air annually, in the lat. of $12^{\circ} \mathrm{N}$. and therefore it might be supposed that the barometer would rise higher and its range be greater at the equator than in higher latitudes: but it is now known from experience, that the range of the barometer is least. at the equator and increases as we approach the poles. Thir seeming contradiction, however, will vanish after the following extracts have been duly considered.

"The mean height of the harometer at the level of the sea, all over the globe, is 30 inches, the weight of the atmosphere, therefore, is the same all over the globe. The weight of the atmosphere depends on its density and height: where the density of the atmosphere is greatest, its height must be the least; and on the contrary, where its density is least, its height must be the greatest. The height of the atmospherc, therefore, must be greatest at the equator and least at the poles; and it must 
decrease gradually between the equator and the poles, so that its surface will resemble two inclined planes meeting above the equator, their highest part.

"A current of air is constantly ascending at the equator, and part of it at least reaches and continues in the higher parts of the atmosphere. From the fluidity of air, it is evident that it cannot accumulate above the equator, but must roll down the inclined plane, which the upper surface of the atmosphere assumes, towards the pole.

"As the heat in the torrid zone nover differs much, the density, and conequently the height of the atmosphere will not vary much. Hence the range of the barometer within the tropics is comparatively small; and it increases gradually as we approach the poles, because the difference of the temperature, and consequently of the deusity of the atmosphere, increases with the latitude."-Thomson's Chemistry, vol. iv. p, 46.

It is abundantly confirmed by experience, that when the chemiral union between those elements and moisture is dissolved, a portion of the air is reduced into its component parts, thermogen, photogen, and water, which recurn again to the earth, either in flashes of lightning, or in showers of rain, hail, or snow.

Metallic rods reaching above the tops of buildings are known to conduct electricity from the air to the earth; and indeed, almost every elevated object is a conductor when the air is highly charged with those elements; whence we may infer, that in a thuidder-storm, a person is much safer in a town, than upon an open plain. I an the more inclinerl to believe the truth of this remark from some phrnomena which came under my own observation.

I was, some years ago, riding along the sea-shore in a very dark night, when it lightned very much at sea, with distant thunder. A very heavy shower came on where I was, which produced illuminations far more briliant than can be well described.

The small end of my whip, and the tips of the ears of my horse, were ornamented with small lamps or globes of fire: every other little projecting point about his head was ornamented in the same manner; and his mane was almost one entire blaze of light. I attempted several times to extinguish these lights by striking them with my whip, but without producing any permanent effect; for no sooner was the water struck off from the parts which were illuminated, than these lights were regenerated by the succeeding drops of rain. These illuminations continued as long as the shower lasted, which might be about a quarter of an hour.

Vol. 44. No. 199. Nov.1814. 
This shower came from the sea; it was about low water, and 1 was riding near the water's eslge, conscquently there were no high objects to attract this clement of combustion before it reached me.

It will be easily understood how these lights were produced from the well known properties of electricity. The drops of rain, being highly clarged with one of the elements of combustion, falling upon objects connected with the earth, the other element was attracted through those objects, and uniting upon the most elevated points, a slow combustion took place, producing the illuminations abore described.

Heat always increases the attraction between the two elements of combustion; but a contrary temperature produces a contrary effect.

In the north polar regions, where the sm never shines during some months, the attraction berween the themogen of the ait and the photogen in the earth being suspended, no heat is generated; hence the most interine cold prevails, till the rays of the sun revisit those latitudes.

And in our winter, the cold air from the north carries off the heat from the surface of the earth, and as the sun's rays seldom reach us at that season of the year, the weather becomes extremely cold, for the reasons mentioned above.

But when the wind blows from the torrid zone, being of a higher temperature than that from the north, attraction takes place between the thermogen, which it contains, and the photogen of the earth, the temperature of the air is soon increased; and if the earth be covered with snow, it is either reduced into water, or converted into atmospheric air. And vegetation under the snow is always found in a forward state, for the thermogen and photogen having attracted each other through the snow, the temperature of the earth is increased above freezing, although the snuw still remains of that point.

This hypothesis will rceeice some support from the following extract taken from my journal.

"March 17, 1814. The snow which began to fall about the 6th instant has been wastivg away for some days, mostly by evaporation. I lave observed for the la's two or three days, little holes in the snow in the grardus, round the plants and sticks which appear above it. These holes are wide at the top and narrow at the bottom, reaching to the ground. QueryMay not these sticks and plants condurt the photogen of the earth into the atmosphere, by winch means so nuch heat is generated as to convert the snow into itmus pherie air; or, to speak in more familiar terms, to cans: erajningion?

"To soive this gitery by expriment, I thoch three rods; one 
of wood, another of metal, and a third of glass. These were stuck through the snow in the garden into the ground, at proper distances from each other. 'Two days afterwards, I examined these rods, and found holes in the snow round the two first similar to those mentioned above; but there was not the least alteration in the snow round the glass rod, glass being a nonconductor of those elements."

But if this experiment be not suficicit to solve the above query, there are other well known phxnomen, from which the same conclusion may be drawn.

$$
\text { Lym, Nov. 9, } 1814 .
$$

Ez. WALFER.

[To he cuntinud.]

LVII. Further Experiments and Observations on Iodine. By Sir H. DAvY, LL.D. F.R.S.V.P.R.I.*

\section{On the triple Compounds containing Iodine and Oxygen.}

1. IN this communication I shall have the honour of presenting to the Royal Society a continuation of the in quiries I have made respecting the chenical agencies of iodine, and the properties of certain of its compounds.

2. I described in my last paper the action of iodine on fixed alkaline lixivia, and the deflagrating salts it forms. In the first experiment which I made on these compounds, I employed the first crystals which fall down from moderately strong solutions of potassa and soda saturated with iodine, which had been purified by being repeatedly acted upon by distilled water: I now find that this process is not sufficient to free the triple compound from the donble compound; and that to obtain them in a state of absolute purity, it is necessary to boil them repeatedly in small guantities of alcohol of specific gravity of from $8 \cdot 6$ to $9 \cdot 2$, which dissolves the double compound, but has little power of action on the triple compound.

The triple compounds, when purified, present soine curious chemical phænomena, which a minute quantity of the double 